\title{
Mass extermination of green toad metamorphs (Bufotes viridis) in Greece
}

\author{
MIKOŁAJ KACZMARSKI ${ }^{1 *}$ \& PRZEMYSŁAW ŻURAWLEW²
}

\author{
${ }^{1}$ Institute of Zoology, Poznań University of Life Sciences, Wojska Polskiego 71c, 60-625 Poznań, Poland \\ ${ }^{2}$ Independent researcher, Żbiki 45, 63-304 Czermin, Poland \\ *Corresponding author e-mail: traszka.com@gmail.com
}

$\mathrm{O}$ n 14 May 2018, during observations in Laganas $\left(37^{\circ} 43^{\prime} 43.1^{\prime \prime} \mathrm{N}, 20^{\circ} 52^{\prime} 26.2^{\prime \prime} \mathrm{E}\right.$, Zakynthos, Greece) on the Ionian coast, aggregations of freshly metamorphosed toads were found on the sandy shores and shallows at the estuary of a small watercourse (Fig. 1A, B). Based on morphological characteristics, individuals were identified as green toads Bufotes viridis, sensu lato in view of the sympatric occurrence of $B$. variabilis and B. viridis in parts of Greece and the unsettled systematic status of the former taxon (Stöck et al., 2006). In the course of a thorough inspection of the site, several thousand dead individuals of this species were found, along with numerous living toadlets (Fig. 1C). The cause of death was poisoning by stabilised chlorine granules, usually used for swimming pool maintenance, which most probably had been poured directly onto the largest aggregations of these amphibians. Granules had also been poured precisely along the margins between the banks and watercourse, so that the toads would not be able to move away from the watercourse (Fig. 1D). The mouth of the watercourse is used intensively by tourists as a place for walks along the sea and to hotels. Thus, in our opinion, this action was deliberate and most probably done by the staff of neighbouring hotels.
The green toad, categorised in the National Red Data Books of Greece as a species of least-concern, is also one of seven amphibian species in Greece protected under national legislation (protected under Presidential Decree 67/1981) (Sotiropoulos \& Lymberakis, 2015), as well as being protected by international law: the Bern Convention (Annex II) and the Habitats Directive of the European Union (Annex IV). Except in the northern parts of its range this is a common or numerous species; however, the basic trend for its populations has been defined as decreasing (amphibiaweb.org, 2019). Among the threats to amphibians in Greece, next to climate change, human activity has been cited, which includes agriculture, pollution, progressive residential development, and the negative impact of tourism (Sotiropoulos \& Lymberakis 2015).

The current example is clearly a case of persecution and may result from an aversion to amphibians and/or the treatment amphibians as if they were pests. In a study conducted by Prokop et al. (2016), almost $31 \%$ of high school students declared their willingness, upon encountering a frog in a garden, to remove it, while $6 \%$ were willing to kill it. Aversion to, and fear of, amphibians is deeply rooted

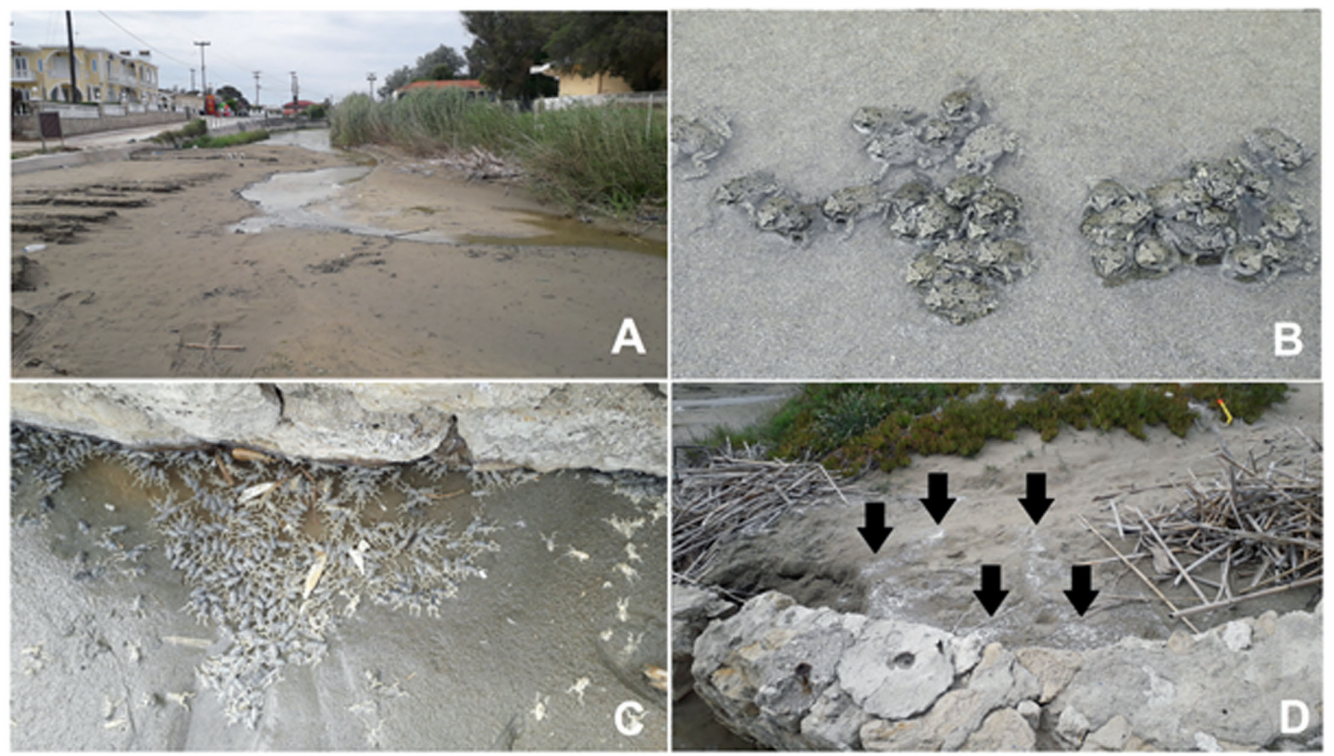

Figure 1. A) Site of aggregations of green toad B. viridis toadlets in the mouth of a watercourse, leading to the lonian Sea in Laganas, B) Live green toad toadlets, C) Photo depicting individuals killed with chlorine granules (about 432 dead individuals) D) The banks of the stream sprinkled with chlorine granules (indicated by arrows), most likely to prevent the movement of toadlets to areas adjacent to the river 
in the human psyche, and these animals very often elicit disgust in people (Frynta et al., 2019). As Frynta et al. (2019) concludes, 'species with a round body shape, short forelegs, small eyes, warts, pink and grey coloration, or dark and dull coloration were perceived as disgusting or ugly'. These features undoubtedly match many amphibian species, including juvenile green toads. Most probably those people who persecute amphibians might view them much more favourably if they were aware of their ecological importance (Prokop \& Fančovičová, 2012).

Actions such as the one we have described here should be openly and firmly condemned. What is more, this is a surprising example of how deeply the transformation of space in the interests of tourism affects nature; not only does it destroy habitats, but animals and plants that do not fit into the idealised space of an 'all-inclusive' hotel are ruthlessly eliminated. It seems probable that if the tourists who are patronising these hotels were made aware of what is being done to the local wildlife for their 'benefit' there would be very strong objections. Local wildlife groups should be encouraged to take appropriate action against what is clearly a wildlife crime.

\section{ACKNOWLEDGEMENTS}

We are grateful to Petros Lymberakis, Jan Kaczmarek, and Piotr Tryjanowski for their valuable comments and guidance in writing the manuscript.

\section{REFERENCES}

Frynta, D., Peléšková, Š., Rádlová, S., Janovcová, M. \& Landová, E. (2019). Human evaluation of amphibian species: a comparison of disgust and beauty. The Science of Nature 106: 41. doi.org/10.1007/s00114-019-1635-8.

Prokop, P. \& Fančovičová, J. (2012). Tolerance of amphibians in Slovakian people: A comparison of pond owners and non-owners. Anthrozoös 25: 277-288.

Prokop, P., Medina-Jerez, W., Coleman, J., Fančovičová, J., Özel, M. \& Fedor, P. (2016). Tolerance of frogs among high school students: Influences of disgust and culture. Eurasian Journal of Mathematics, Science, and Technology Education 12: 1499-1505.

Sotiropoulos, K., Lymberakis, P. (2015). Decline and conservation of amphibians in Greece, In: Amphibian Biology, Volume 11, Part 4: Status of Conservation and Decline of Amphibians: Eastern Hemisphere: Southern Europe \& Turkey. Heatwole, H., Wilkinson, J.W. (Eds). Pelagic Publishing, 362 pp.

Stöck, M., Moritz, C., Hickerson, M., Frynta, D., Dujsebayeva, T., Eremchenko, V., Macey, J.R., Papenfuss, T.J. \& Wake, D. B. (2006). Evolution of mitochondrial relationships and biogeography of Palearctic green toads (Bufo viridis subgroup) with insights in their genomic plasticity. Molecular Phylogenetics and Evolution 41: 663-689.

Accepted: 4 October 2019 